\title{
The Population Situation in Finland and the Population Policy it Requires
}

In order to bring family and population policy questions to the attention of the Government and the political parties Väestöliitto, the Finnish Population and Family Welfare Federation, has prepared 14.10.1975 the following ten points about the population situation and the population policy that should be undertaken in Finland.

1. The population question is considered one of the so-called global problems, as are the nutrition, energy, raw material and environmental problems. In order to discuss these global problems the United Nations and its special agencies have held extensive conferences. The world population program adopted at the UN population conference held in Bucharest in 1974 is more a collection of well-meaning advice and statements on how things stand than an instrument that would directly and effectively influence world population development. The current world population (3700 million people) is expected to double by the year 2000 .

2. According to the world population program the formation and realization of population policy is the sovereign right of each state. Then again »all couples and individuals have the basic right to decide freely and responsibly the number and spacing of their children and to have the information, education and means to do so». The state's attempts to preserve and even to increase the size of the population on one hand and the provision of family and sex education and contraceptives on the other do not conflict. The measures used in Finnish population and family policy fit in well with the aims and principles incorporated in the world population program.

3. In Finland the population problem has, until now, been understood often in a narrow sense, referring only to the size of the population, although equally important are, for example, the population's age and sex structure, educational level and regional distribution.

In our country questions concerning population policy have for the present been minor problems overshadowed by other questions. They have not been seen as an entirety nor does population policy as a whole belong under the administration of any ministry. The areas of jurisdiction of the different ministries should be clarified in this respect. The population question will be included in planning social development policy, when, in accordance with legislation on regional development, plans for regional development are drawn up, which will also include planned forecasts of jobs and population. 
4. Birth rate. The following list of figures shows the development of the birth rate in Finland since the time of independence.

\begin{tabular}{ccc} 
year & \multicolumn{2}{c}{ live births } \\
& number & $\begin{array}{c}\text { per thousand } \\
\text { inhabitants }\end{array}$ \\
1920 & 84700 & 27.0 \\
1930 & 75200 & 21.8 \\
1940 & 65800 & 17.8 \\
1950 & 98100 & 24.5 \\
1960 & 82100 & 18.5 \\
1970 & 64600 & 14.0 \\
1973 & 56700 & 12.2 \\
1974 & 62400 & 13.3
\end{tabular}

The birth rate figures reached their peak in 1947 (108 168 children) and their lowest point in 1973 . The birth rate of the whole world is $35 \%$, in the Soviet Union $18 \%$, elsewhere in Europe about $15 \%$ and lowest in the German Federal Republic and the German Democratic Republic, about 10-11 \%o.

Our country has 4700000 inhabitants, which is more than there has ever been. During peace time the population has risen every year except in 19691970 , when it dropped because of migration to Sweden.

5. Mortality. Population growth - about 19000 persons in 1974 - has been based in the last few years almost entirely on a decline in mortality, that is a growth in the mean length of life. However, the expectation of life at birth of Finns is already so high that a drop in mortality in the future will not increase the size of the population very much. Infant mortality has been forced down to an extremely low level, 10.9 per 1000 live births, and the possibility of lowering the mortality of the working-age population and of the elderly from the present figures is limited. There is, however, a need to lower them, because the average life expectancy of 30 -year-old Finnish males is 38.4 years and of females 45.8 years. The figure for men is Europe's lowest, the figure for women is below the European average.

6. External migration. There are over 110000 Finnish workers living in Sweden. In the 1960 s Finland lost through migration a total of 142000 persons and an average of 7000 workers per year. In the 1970 s migration became stabilized and for several years return migration was more popular than emigration. But beginning August 1974, and each month since then, emigration has been greater than return migration. According to a migration study made at the Research Institute of the Finnish Economy three-fourths of the people who migrated to Sweden said they had done so for economic reasons, such as difference in standard of living and wages $(37 \%)$ of the unemployment/underemployment situation $(25 \%)$.

Finland is the only country with a high standard of living that has had relatively significant out-migration in recent years. If migration were to con- 
tinue on a large scale Finland would be exposed as a developing country, which is often recognizable by the production below cost of the most expensive factor in production, people, for its better-off neighbors.

7. Internal migration. The population of the statistical areas lying in the developing regions continued to grow until the end of 1964 . Since then the decrease in the population has been continuous, and around the years 19691970 the population decreased very rapidly. At the end of 1969 the population of the developing areas dropped below the figure in the 1960 census. Hundreds of Finnish communes are so-called end-of-the-world communes, the term used in the National Planning Office. The term refers to communes where mortality is higher than the birth rate. According to population forecasts mortality for all of Finland will probably rise above the birth rate during the 1990s.

The difficulties caused by migration to both out-migration communes and in-migration communes are well known, and there is probably no need to list them here. Definitely unbalanced population development can be noted in different areas of Finland. While the total population grows, shrinks or varies over a long period of time, it simultaneously causes, either directly or indirectly, permanent or wide-ranging under- or over-use of the labor force and other production factors, a cessation in neccessary services or a protacted delay in services that would be in keeping with the size and structure of the population.

In most communes, and even in most provinces, the situation is more serious than it may seem merely on the basis of population figures. Population forecasts, which form the basis on which the economic forces and the government make their decisions concerning further development, have predicted a continuous decline. Therefore, enterprises and services disappear from an area and no new ones are founded. The forecast has become self-realizing. This is why we need regional population plans and programs that would set population goals. If these goals are not reached, a warning signal would go off and different forms of support would be activated.

Every year over 200000 Finns move to another commune. In many communes in the developing areas, and even in many in the other areas, the population structure, which features a male majority, aging and shrinkage, is so liable to injury that even a slight drop may lead to the loss of the prerequisites to society's existence, resulting in the migration of the population - not only from villages but even from entire communes. All this should be taken into account when forming labor and economic policy, especially since there is a broad political consensus on regional development policy.

8. Labor force. The age structure of the population is the following:

$\begin{array}{ccccc}\text { age } & 1950 & 1970 & 1975 & 2000 \\ -14 & 30 \% & 24.3 \% & 21.8 \% & 16.5 \% \\ 15-59 & 60 \% & 61.4 \% & 62.6 \% & 66.0 \% \\ 60- & 10 \% & 14.3 \% & 15.6 \% & 17.5 \%\end{array}$


The percentage of children and youth in the population is shrinking constantly. In 100 years current development may yet lead to an age structure with elderly people making up almost $25 \%$ and children and youth making up only a little more than $10 \%$. The percentage in the labor force will continue to grow because of the large age groups and the previously high birth rate, but when the large age groups retire after the year 2010, the aging of the population will gain momentum and the labor force will decrease in size.

Net increase in the working-age population (15-64 years old) during fiveyear periods is as follows:

$\begin{array}{ll}1970-75 & +125000 \text { persons } \\ 1975-80 & +90000 \text { persons } \\ 1980-85 & +66000 \text { persons } \\ 1985-90 & -5000 \text { persons }\end{array}$

These calculations presuppose that in the future in- and out-migration will equal each other.

Everyone of working age is not on the labor market: for example students, housewives, pensioners and those under institutional care. According to calculations drawn up at the National Pensions Institute the number of people on work disability pensions will increase in the latter half of this decade by 60000 . In other words, two-thirds of the increase taking place in the next few years in the working-age population will be needed to replace those who will be pensioned because of work disability.

In recent years the increase in the labor force has mainly been composed of women. In Finland the portion of working-aged women currently employed outside the home is greater than in almost any other Western country. Getting an even larger share onto the labor market will require wide-ranging, labordemanding measures in other sectors of social development policy, for example, in children's day care and in taxation and wage policies - if this is desirable in the first place.

There are, of course, more labor force reserves in the developing areas than in Southern Finland, but as shown above, they, too, are running out. Nor will agriculture be able to act as a labor force reserve any longer. Of the remaining agricultural population only one fourth is under 40 years of age. Because the parents in farm families are relatively aged, only about 10000 children are born per year, while at the same time 35000 people actively engaged in agriculture leave it, some retire, some go into other fields of work and some die. But even if every child of these farm families became a farmer in turn, the size of the agricultural population would still decrease rapidly.

9. The future Finnish population. Population change is affected above all by fertility and migration. 
Women born in 1905-20 had an average of 2.5-2.7 children

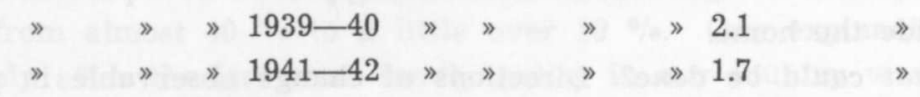

Finland's fertility figures are the fourth lowest in Europe. Women have their children at an increasingly earlier age. In 1974-1975 the rise noted in the number of births has not been caused by the fact that the youngest age groups (20-24-year olds) would be having more children, but rather that the slightly older age group (25-29-year-olds), after having postponed having children, are now giving birth at a later age than the age groups preceding them.

Since 1969 population growth in Finland has been based mainly on an increase in length of life and a decrease in mortality. Since 1969 our country's population has not renewed itself, that is, the new generations are smaller than preceding generations. In order that the population would have renewed itself, 63000 more children should have been born in 1969-1974. If Finland's population were to renew itself on the current level, an average of 2.3 children should be born per woman, which is over 70000 per year. According to one study. Finns feel that the ideal number of children in a family is $2.5-2.8$ children. Actually, however, much fewer are born.

Calculations used in planning in Finland come to the conclusion that the population of Finland will increase until the $1990 \mathrm{~s}$, rising to over 4.9 million, and then will begin to decrease, which may lead in the year 2100 to a population of only 3 million. ECE's calculations show that the population of Norway, for example, will be larger in the year 2000 than that of Finland.

One calculation shows that if an equal number of children are born in Finland as in 1974, 62000 , then the total population would rise in the year 2010 to five million and decrease after this so that one hundred years later it would be equal to today's population. This alternative, which would realize relatively stable population development, contains, however, certain prerequisites:

- the fertility per family of Finns being born in the next decades should be much higher than it is now,

- out-migration should not cause population loss, and

- the average expectation of life at birth should be at the level it is in Sweden.

Thus the life span of the European family has gone through some essential changes, which lead to many other changes in society and in the people's way of life. The distance between two generations is smaller, children are brought up mainly by young parents, women who have reached $30-35$ years of age are searching for alternatives to a life centered around the home. This direction will not change unless special measures are taken, because the urban way of life and the accompanying small-family-ideal are becoming ever more prevalent, good contraceptive information and contraceptive methods and the abortion laws make it possible to regulate the birth rate, and economic problems 
and the rise in the level of education increasingly draw both parents to employment outside the home.

10. What could be done? Directions of change observable in population development usually take place relatively slowly, their significance and consequences are discovered only decades later, perhaps. Current problems take up so much interest and energy in political life that politicians usually do not have any time left to sufficiently ponder the consequences of population development. It is, however, a fact that the size, structure, education and distribution of the population and many other factors pertaining to population determine the ability of a nation to function, and the aim of social development policy is the interests and welfare of the population. Therefore, social development policy and the policies set by political factions cannot avoid taking a stand on population development.

Figure 1. The structure of social expenditures in 1954-1971.

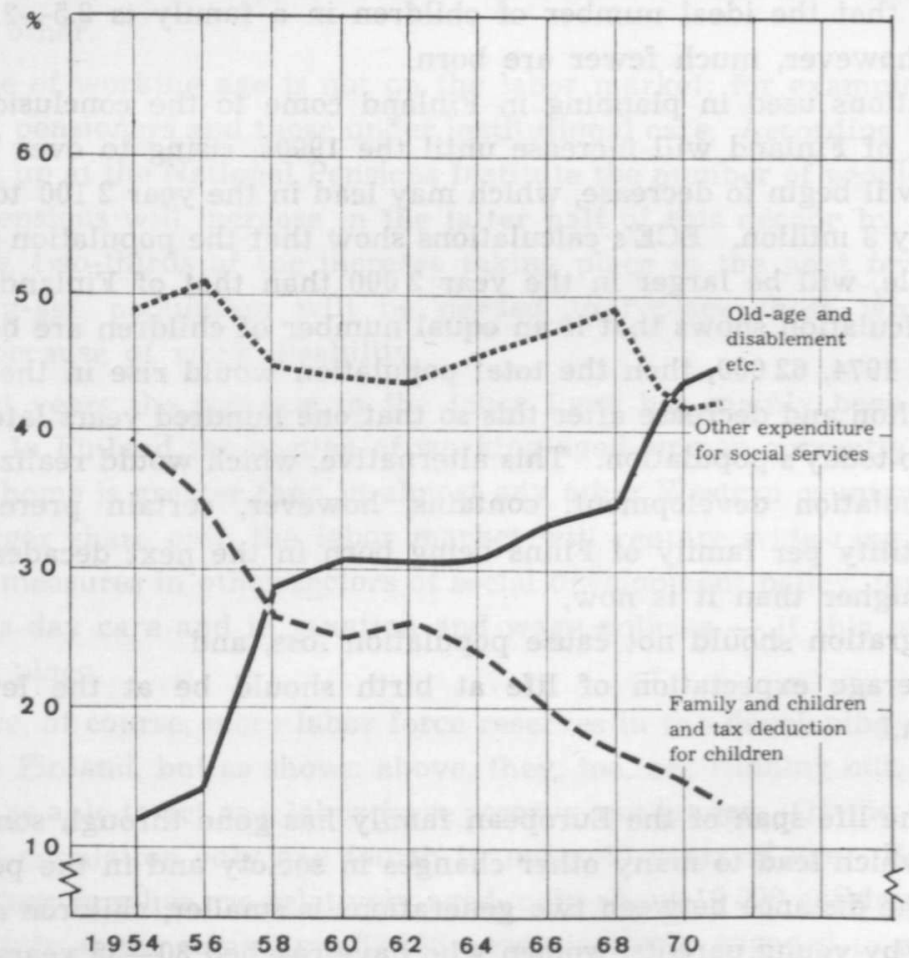

The percentage of the national product used for social expenditures in the 1960 s has grown more than the experts had predicted (Figure 1). If we study the structure of social expenditures in our country between 1954-1971, we can see that while the percentage of pension and work disability policy has grown 
from a little over $10 \%$ to over $40 \%$, the percentage of family policy has dropped from almost $40 \%$ to a little over $10 \%$. One explanation is that immediately after the last wars family policy in our country was relatively effective and diversified and that the figures mentioned above only prove that the other sectors of social policy have developed sufficiently. On the other hand, it should be mentioned that this development has meant not only a relative decrease but also an absolute decrease in the percentage taken up by family policy, and that in Sweden, for example, corresponding development injurious to family policy has not taken place. As the number of pensioners and the work-disabled, who have voting power, has risen substantially, and pensioners have begun to organize themselves politically, apparently more attention has been paid to their aspirations than to the needs of children and infants.

In the last few years politicians have become interested in population and family policy. Many political parties have adopted a population and family policy program, and many members of the current Parliament have, when interviewed emphasized their desire to improve family policy. The supplementary program of later government contained a section on family policy, and certain practical improvements have been implemented in equalizing family expenditures, in day care and in housing policy. The way of thinking in political circles has become more favorable toward family and population policy - even if the reason for the change has often been more a fear of a labor force shortage and the threat of a decrease in population than the idea that society should, on principle and on the grounds of justice, reimburse much more of the expenses accrued by families with children than it now does. Previous experience has shown that the field of population and family policy continues to need interest groups that are sufficiently able to act independently, are based on expert advice and are coherent.

In order to treat and solve family and population policy questions in the manner and at the level demanded by their true significance, it would be necessary for their administration to adopt population and family policy as a special section in the Government's program, to give more clear-cut responsibility for the policy's administrative preparation and realization to the Ministries, to include the size and quality of the population as a significant factor in planning at the communal, provincial and national levels, and to establish a population policy council according to the recommendations of the Bucharest conference.

Many countries in Europe have already begun forceful family policy action. Here in Finland, in addition to measures aimed at strengthening the population basis in different areas, we should strive for a development program, which would cover the entire country and include the industrial, housing, labor force, family and the other social policy sectors, and which would assumably have a desirable effect on in- and out-migration as well as on the development of the birth rate, which all regulate the total development of the population. 
Actions which seem timely at the moment are:

1. Making the general atmosphere more favorable to children and families, in addition to which the needs of children and families should be taken into account in community design and societal and community planning.

2. Helping young couples acquire a home on lenient terms of payment.

3. A substantial increase in the child subsidy for children under 7 years of age, so that five years from now the subsidy per child would be equal to one third of the minimum wage.

4. Placing the care at home of children under school age on a par with employment outside the home according to the number of children and the number of years the care has been given, so that these years would entitle the person to sufficient social and pension security,

5. Developing day care services and establishing a homemaking support system,

6. Reintroducing the home establishment loan, sufficient in size and in a renewed form, and

7. Supporting research on population and the family, surveillance of population development and the development of population projections.

Errors made in population policy show up in general education after $10-20$ years, in labor force questions not until a period of $25-30$ years. The time interval of population policy planning is longer than in any other sector of social planning, and that is where the difficulty lies.

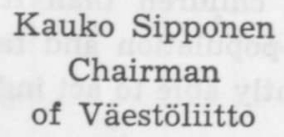

Jouko Hulkko

Managing director

of Väestöliitto 